\title{
Retrospective comparison of lens implant surgery and cataract surgery in a provincial unit
}

\author{
J WATTS \\ From the Royal Victoria Hospital, Bournemouth
}

SUMMARY Evidence is presented which shows that the extracapsular cataract extraction technique combined with a Sinsky type posterior chamber implant is as safe a procedure as routine intracapsular surgery. Its results as reflected in the patient's satisfaction are superior.

This study was undertaken, firstly, to compare the results obtained by implant surgery with those obtained by routine cataract extraction, and, secondly to determine whether there was any difference in the success rate between the various implants available. In this relatively early period of implant surgery in the United Kingdom three major types of implant were available, and by chance each of three of the consultants in this unit began by favouring a different type. We were thus able to compare the following procedures: (1) intracapsular cataract extraction and iris clip implant (Federov type); (2) intracapsular cataract extraction and anterior chamber implant (Choyce type); (3) extracapsular cataract extraction and posterior chamber implant (Sinsky type).

Although each of the three consultants favoured one type of implant, they each used both of the other types at some time, so that the results do not reflect on individual surgeons.

\section{Patients and methods}

All patients who received an implant from May 1979 onwards to June 1983 and for whom there was a follow-up of at least six months were recalled to assess the success of the implant surgery they had undergone. The results were compared with a series of routine intracapsular cataract extractions performed during the same period of time.

During the four-year period from May 1979 to June 1983, 225 patients received an implant following cataract extraction. Of these, 181 were assessed. Sixteen patients had died and 28 were too ill or unable to attend. They received implants in the Correspondence to Mrs J Watts, FRCS, Royal Victoria Hospital, Poole Road, Westbourne, Bournemouth BH4 9DG. proportion shown in Table 1 . Out of 181 patients seen with implants 100 were female and 81 male. The average age was 74.5 years and the average follow-up 17 months.

One hundred and eighty-one patients who had undergone routine intracapsular cataract extraction without an implant were selected by taking the consecutive case from the operating book. Of these 181,110 were female and 71 were male. Their average age was 72.7 years and the average follow up was 18 months. Thus the two groups represent a similar cross section of our cataract patients.

\section{Results}

The visual acuity results show that $166(92 \%)$ of all implanted eyes saw $6 / 12$ or better when the vision was corrected as compared with $150(83 \%)$ of all nonimplanted eyes, which saw $6 / 12$ or better with their aphakic correction. Fig. 1 shows the visual results obtained with the three types of implant. There was no significant difference $(p=0.05)$ between the three types of implant in either unaided or aided visual acuity.

Only $14(8 \%)$ of the implanted eyes showed a visual acuity of less than $6 / 12$. However, $31(17 \%)$ eyes with no implant were unable to gain better vision than 6/12. In most cases, this was due to existing eye disease at the time of operation (Table 2) and does

Table 1 Implant numbers

\begin{tabular}{lcc}
\hline Type of implant & Number & $\%$ of total \\
\hline Iris clip & 81 & $45 \%$ \\
Anterior chamber & 44 & $24 \%$ \\
Posterior chamber & 56 & $31 \%$ \\
Total & 181 & \\
\hline
\end{tabular}


BAR CHARTS OP VISOAL ACUITY RESOLTS FOR 3 TIPES OP IMPLANT

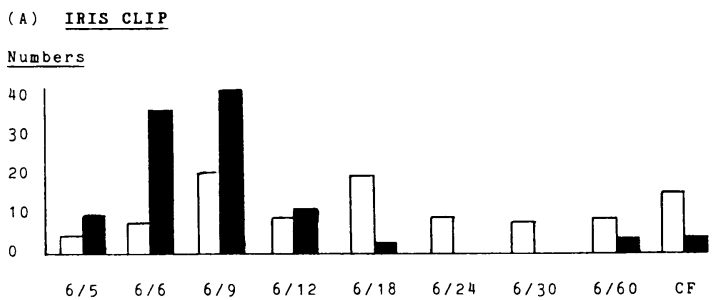

Visual Acuity

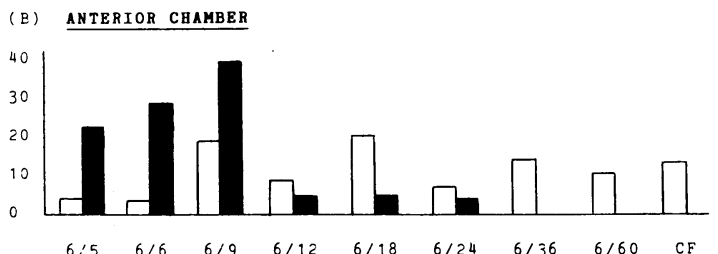

(C) POSTBRIOR CBAMBER

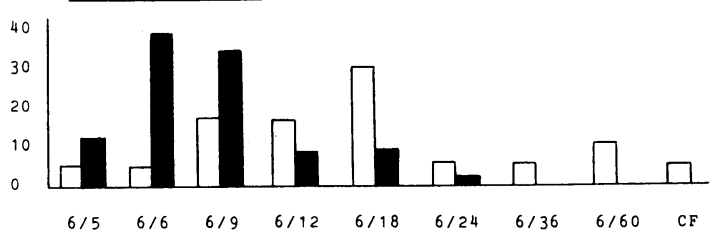

Fig. 1 Visual acuity results for three types of implant. $C F=$ counting fingers.

not reflect on the method of surgery or the correction of aphakia. (Two cases of cystoid macular oedema were noted in the implanted eyes and these are discussed in the next section.)

Complications arose in $23(13 \%)$ of the implanted eyes (three eyes had more than one complication) and in seven $(4 \%)$ of the eyes following routine intracapsular cataract extraction. The analysis of complications was divided up into those occurring early either during the operation or in the immediate postoperative period (Table 3 ) and those occurring

Table 2 Causes of reduced visual acuity $(<6 / 12)$

\begin{tabular}{lcc}
\hline & Implanted eyes & Non-implanted eyes \\
\hline Senile macular degeneration & 7 & 12 \\
Cystoid macular oedema & 2 & - \\
Amblyopia & - & 5 \\
Chronic simple glaucoma & - & 5 \\
Diabetic retinopathy & - & 2 \\
Corneal decompensation & - & 2 \\
Central retinal vein occlusion & 1 & 1 \\
Retinal detachment & - & 1 \\
Others & 4 & 3 \\
Total & 14 & 31 \\
\hline
\end{tabular}

Table 3 Operative and postoperative complications

\begin{tabular}{llllll}
\hline Procedure & $\begin{array}{l}\text { Vitreous } \\
\text { loss }\end{array}$ & $\begin{array}{l}\text { Pupil } \\
\text { block }\end{array}$ & $\begin{array}{l}\text { Iris } \\
\text { prolapse }\end{array}$ & $\begin{array}{c}\text { Hypopyon Raised } \\
\text { intraocular } \\
\text { pressure }\end{array}$ \\
\hline Routine & 3 & - & - & - & - \\
$\begin{array}{l}\text { Iris clip } \\
\begin{array}{c}\text { Anterior } \\
\text { chamber }\end{array}\end{array}$ & 1 & - & - & 2 & 2 \\
$\begin{array}{c}\text { Posterior } \\
\text { chamber }\end{array}$ & - & 1 & 1 & - \\
\hline
\end{tabular}

*Plus vitreous loss.

†Also required repositioning.

Table 4 Latecomplications

\begin{tabular}{|c|c|c|c|c|c|}
\hline Procedure & $\begin{array}{l}\text { Capsule or } \\
\text { membrane } \\
\text { thickening }\end{array}$ & $\begin{array}{l}\text { Corneal } \\
\text { decompen- } \\
\text { sation }\end{array}$ & $\begin{array}{l}\text { Retinal } \\
\text { - detachment }\end{array}$ & $\begin{array}{l}\text { Cystoid } \\
\text { tmacular } \\
\text { oedema }\end{array}$ & $\begin{array}{l}\text { Re- } \\
\text { positioning }\end{array}$ \\
\hline Routine & - & 2 & 2 & - & - \\
\hline Iris clip & 2 & - & - & 1 & 7 \\
\hline $\begin{array}{l}\text { Anterior } \\
\text { chamber }\end{array}$ & & - & - & $1^{*}$ & - \\
\hline $\begin{array}{l}\text { Posterior } \\
\text { chamber }\end{array}$ & & - & - & - & - \\
\hline
\end{tabular}

*Plus vitrcous loss.

Table 5 Numbers of complications

\begin{tabular}{lcc}
\hline Operation & Number & Percentage \\
\hline Routine cataract cxtraction & 7 & 4 \\
Iris clip & $16^{*}$ & 20 \\
Anterior chamber & $6^{*}$ & 14 \\
Posterior chamber & 4 & 7 \\
\hline
\end{tabular}

${ }^{*}$ Threc cyes suffered more than onc complication.

later during the follow-up period (Table 4). Two other patients with anterior chamber lenses commented on some tenderness on touching the eye, but on the whole the patients were very satisfied with their operation.

The number of eyes in which complications arose is shown in Table 5. $x^{2}$ tests were applied to these numbers with the following results. There was a significantly greater number of complications in eyes receiving an iris clip or an anterior chamber implant in comparison with routine cataract extraction. However, the posterior chamber implant procedure produced no significant increase in complications $(p=0.05)$. In addition the posterior chamber implant procedure produced significantly fewer complications in comparison with the iris clip implant procedure but not in comparison with the anterior chamber implant procedure $(p=0 \cdot 05)$.

$\cos \mathrm{T}$

With so much attention on expenditure in the 
National Health Service (NHS) it was thought of interest to estimate the additional cost of correcting the vision of an aphakic eye by using an intraocular implant rather than by aphakic glasses. Two factors were considered relevant.

(1) Operative. There is no doubt that there is an increased use of both Healonid (containing sodium hyaluronate $10 \mathrm{mg} / \mathrm{ml}$ ) to facilitate lens implantation and Miochol (acetylcholine 1\% and mannitol 3\%) to ensure good pupil closure when an implant is introduced as compared with routine cataract extraction. In this series Healonid was used in only $12(7 \%)$ of the implant operations: five iris clip; six anterior chamber, and one posterior chamber. Miochol was used in $43(24 \%)$ of the implant operations: 15 iris clip; 20 anterior chamber, and eight posterior chamber. These drugs are expensive: Healonid costs $£ 30.00$ a vial and Miochol $£ 6.75$ a vial, but their use is not routine.

(2) Refractive. The average cost to the NHS of an intraocular implant is $£ 80.00$. If a reading correction is required for the implanted eye, the spectacle lens will cost less than $£ 6.00$. The average cost to the NHS of a bifocal aphakic spectacle is $£ 34.00$. More often than not more than one lens is required and replacements are necessary.

Thus the average additional cost of correcting aphakia with an implant is shown to be less than $£ 50.00$.

\section{Discussion}

In 1978 iris fixation lenses were implanted most frequently.' At that time, Galin ${ }^{2}$ reported that, though the visual acuities obtained with the iris clip implants were no different from those obtained by routine cataract surgery without implant, there was a significant increase in the incidence of dislocation and membrane formation. This is confirmed in our series. However, since 1980 the use of iris clip implants has declined in favour of the use of either anterior chamber or posterior chamber implants.

In some hands the anterior chamber implant gives excellent results. It has the advantage that it is best suited to an intracapsular cataract extraction, a technique which has been practised for years. ${ }^{3}$ Others have favoured an extracapsular technique combined with a posterior chamber implant. Several reports have been published comparing the advantages and disadvantages of intra- and extracapsular surgery, ${ }^{4}$ and, though there is evidence to suggest a lower incidence of cystoid macular oedema and of retinal detachment following extracapsular surgery, there is the incidence of thickening of the posterior capsule to be considered. The reported number of eyes requiring capsulotomy varies widely, from 5 to $50 \%$ after three years, and no long-term figures are yet available. In our series, with a short follow-up, only two patients showed a thickened capsule, that is, $4 \%$ after 18 months.

Data from the FDA report' show that posterior chamber lenses give significantly better visual acuity results than other types-but the report admits this may be the result of better case selection, as other implants would be used if operative complications arose during the procedure. In this hospital the extracapsular cataract technique combined with posterior chamber implant is now used as routine by all three surgeons cited in this report unless a specific contraindication exists.

\section{CONCLUSION}

In this paper it has been shown that the use of extracapsular cataract technique combined with the implantation of a posterior chamber lens is a safe procedure. The quality of vision thus gained is much better than with aphakic glasses. Useful vision returns immediately, and the patient is inconvenienced only by his few days in hospital. Though the procedure costs more than cataract extraction followed by aphakic glasses, the extra cost must be justified to meet patients' expectations, which are now very high indeed.

I am grateful to all the consultants at the Royal Victoria Hospital, Westbourne, for allowing me to study their paticnts and to $\mathrm{Dr} N$ Joshi, who helped to collect the data. I am also grateful to Mr M Robertson for statistical advice and to Mrs Jane Dunlop for typing the script.

\section{References}

1 Stark WJ, Worthen D M, Holloday J T. The FDA report on intraocular lenses. Ophthalmology (Rochester) 1983; 90: 311-7.

2 Galin MA. Iris supported lens implantation and simple cataract extraction. An analysis of data Trans Ophthalmol Soc UK 1977; 97: 74-7.

3 Absolon MJ. Why I do intracapsular extraction and use the Choyce MkIX AC implant. Trans Ophthalmol Soc UK 1983; 103: 191-4.

4 Rich W. Advantages and disadvantages of different methods of senile cataract surgery. Trans Ophthalmol Soc UK 1982; 102: 407-9.

Accepted for publication 17 October 1985. 